\title{
Do fonológico ao discursivo: hipóteses sobre a produção da chamada "fala telegráfica" no contexto das afasias
}

DOI: http://dx.doi.org/10.21165/el.v49i1.2624

\section{Rosana do Carmo Novaes-Pinto'}

\section{Resumo}

Os estudos sobre a chamada "fala telegráfica" são, em geral, desenvolvidos no contexto das investigações sobre o agramatismo. Essa produção caracteriza-se pela omissão e/ou substituição de morfemas livres ou flexionais, com predominância de palavras de classes abertas e tem sido, na maioria dos estudos linguísticos, atribuída a um déficit de natureza sintática (GRODZINSKY, 1984). Entretanto, há autores que a relacionam a um distúrbio de acesso lexical, predominantemente morfológico (BRADLEY et al., 1980), enquanto outros afirmam tratar-se de dificuldades no acesso fonológico (KEAN, 1985). Embora em menor número, há trabalhos que destacam sua natureza predominantemente pragmática (KOLK et al., 1985; NESPOLOUS, 1997). Caramazza e Berndt (1985), partindo da diversidade de perspectivas, caracterizam o agramatismo como um "déficit multicomponencial". Este artigo visa apresentar uma abordagem integrada dos níveis linguísticos (JAKOBSON, 1954; COUDRY, 1988 [1986]), à luz da Neurolinguística de orientação enunciativodiscursiva, tendo como foco a produção de "fala telegráfica".

Palavras-chave: afasia; agramatismo; fala telegráfica; níveis linguísticos; neurolinguística.

1 Universidade Estadual de Campinas (UNICAMP), Campinas, São Paulo, Brasil; ronovaes@terra.com.br; https://orcid.org/0000-0002-4413-0099 


\title{
From phonological to discursive: hypothesis about the production of the so-called telegraphic speech in the context of aphasia
}

\begin{abstract}
Studies on the so-called "telegraphic speech" are in general developed in the context of agrammatism investigations. This production is characterized by the omission and/or substitution of free or inflectional morphemes, with predominance of open-class words, and has, in most linguistic studies, been attributed to a syntactic deficit (GRODZINSKY, 1984). However, there are authors who relate it to a lexical retrieval disorder, predominantly morphological (BRADLEY et al., 1980), while others claim to be phonological access difficulties (KEAN, 1985). Although in fewer numbers, there are works that highlight its predominantly pragmatic nature (KOLK et al., 1985; NESPOLOUS, 1997). Caramazza \& Berndt (1985), starting from the diversity of perspectives, characterize agrammatism as a "multicomponential deficit". This paper aims to present an integrated approach of linguistic levels (JAKOBSON, 1954; COUDRY, 1988[1986]) enlightened by the enunciativediscursive Neurolinguistics, focusing on the production of telegraphic speech.
\end{abstract}

Keywords: aphasia; agrammatism; telegraphic speech; linguistic levels; neurolinguistics.

\section{Introdução}

O estudo da afasia sofreu uma transformação radical na última década. Outrora província restrita de neurologistas, neuropsicólogos e fonoaudiólogos, o estudo da afasia passou a ocupar um lugar importante na linguística e na psicolinguística. Os pesquisadores consideram a afasia não apenas como um campo de teste para modelos de capacidade linguística normal, mas também como um importante domínio de dados que pode desempenhar um papel crucial na construção de modelos de capacidade linguística normal. (KEAN, 1985, p. xi, tradução nossa²).

O estudo das categorias clínicas - dentre as quais o agramatismo - tem sido de extrema relevância no campo das pesquisas neuropsicológicas e neurolinguísticas, visando compreender a organização e o funcionamento da linguagem, bem como sua interação com as demais funções cognitivas. A partir de categorias delimitadas no campo das patologias, são postulados modelos psicolinguísticos de "processamento". Embora se constituam como "modelos", alguns acabam por estabelecer relações diretas entre

2 No original: "The study of aphasia has undergone a radical transformation in the last decade. Once the restricted province of neurologists, neuropsychologists, and speech therapists, the study of aphasia has come to occupy an important place in linguistics and psycholinguistics. Researchers look to aphasia not only as a testing ground for models for normal linguistic capacity but also as an important domain of data that can play a crucial role in the construction of models of normal linguistic capacity". 
aspectos da linguagem e áreas cerebrais específicas. As categorias clínicas, assim, têm servido como um lugar privilegiado para testar e/ou validar teorias acerca da autonomia, da interação ou da integração dos níveis linguísticos (NOVAES-PINTO, 1999). Um exemplo ao qual costumo me referir para ilustrar a relação do modelo com uma suposta realidade neuropsicológica ${ }^{3}$ é a seguinte afırmação de Menn e Obler (1990, p. 4, grifos meus):

A Neurolinguística, como ramo da Neuropsicologia, tem por objetivo construir uma teoria de como a linguagem é processada no cérebro normal; o neurolinguista estuda a afasia na tentativa de relacionar a lesão a estruturas cerebrais específicas, com o distúrbio de aspectos específicos do desempenho ou do conhecimento da linguagem. Quanto mais delimitado for o déficit, maior a esperança de se apontar para um determinado processo envolvido no distúrbio de uma certa capacidade, e talvez, portanto, seu substrato neurológico.

O aperfeiçoamento das técnicas de neuroimagem tornou possível indicar com precisão as áreas cerebrais acometidas por um episódio neurológico para fins clínicos (diagnósticos, tratamentos cirúrgicos e prognósticos) e permitiu também o desenvolvimento de pesquisas acerca das estruturas anatômicas envolvidas na realização de tarefas cognitivas complexas ${ }^{4}$ (NOVAES-PINTO, 2011). Como vimos na citação anterior,

3 Tenho me referido criticamente a essa postura teórica, bastante recorrente na literatura, como perspectiva "neo-localizacionista". A esse respeito, trago um trecho de Novaes-Pinto (2010, p. 272) que sintetiza esta noção: "Ao contrário das técnicas utilizadas por Gall e seus seguidores, no século XIX, que apalpavam os cérebros dos pacientes nas autópsias para descobrir protuberâncias ou lesões que justificassem o estabelecimento de seus mapas frenológicos, a utilização da neuroimagem se estabelece, no final do século XX e no início do século XXI, como o instrumento mais respeitado para revelar verdades acerca do funcionamento cerebral. A chamada 'década do cérebro', que se iniciou em 1991, possibilitou um avanço sem precedentes no seu conhecimento científico. Segundo Damásio (1997), muitas descobertas foram possíveis graças à utilização da ressonância magnética e de reconstruções tridimensionais in vivo, bem como o estudo das lesões, que permitiram uma nova onda de experimentos cognitivos, ajudando a esclarecer e a transformar a visão clássica a respeito do funcionamento cerebral. [...] Luria (1976) afirma que o desenvolvimento tecnológico permitiu o surgimento da Neurologia Clínica e da Neurocirurgia, o que, por sua vez, possibilitou avanços nos estudos dos mecanismos cerebrais. Entretanto, apesar desse avanço, o autor afirma que questões relativas ao seu funcionamento - ao cérebro em ação -, estão ainda por desejar melhor tratamento teórico".

4 A Ressonância Magnética Funcional (RMf), uma das técnicas de neuroimagem mais utilizadas nas pesquisas neuropsicológicas, permite observar a atividade das áreas cerebrais "convocadas" para a realização de uma determinada tarefa. Isso ocorre porque tais áreas demandam um aumento dos níveis de oxigênio no cérebro, provido pelo fluxo sanguíneo. A imagem obtida, entretanto, não é uma "fotografia" do cérebro, no momento exato em que a tarefa é realizada. Há, segundo os especialistas, um delay entre o tempo real e o tempo em que a imagem é visualizada. Além disso, as imagens têm também a interferência de variáveis individuais, anatômicas, sobretudo com relação ao calibre de veias e artérias, por exemplo. Estas questões não diminuem, de forma 
quanto mais circunscrita a lesão, maior a probabilidade de se compreender o papel de uma determinada área para um processo motor ou cognitivo. Menn e Obler (1990), entretanto, deixam entrever a crença de que a lesão compromete aspectos específicos do "conhecimento" ou do "desempenho" da linguagem" - hipótese fundada em princípios da teoria gerativa, que orientou a grande maioria dos estudos na segunda metade do século XX. O ponto mais questionável, ao meu ver, é a tentativa de relacionar de forma direta aspectos envolvidos na produção ou na compreensão da linguagem a substratos neurológicos, crítica feita pelos neuropsicólogos não-localizacionistas como Jackson (1874), Freud (1871) e Luria (1973), dentre outros, já no final do século XIX e início do século XX.

Estudos de renomados pesquisadores foram organizados por Kean (1985) no célebre volume intitulado Agrammatism e colocaram em cheque a chamada "Teoria do Déficit Sintático Central", abrindo espaço para que novas hipóteses fossem elaboradas para explicar, sobretudo, a produção da chamada "fala telegráfica". Esta é ora compreendida como uma falha de acesso fonológico, ora como falha de acesso lexical, como dificuldade na organização sintática ou ainda desenvolvida como adaptação dos afásicos a diferentes contextos pragmáticos. Trata-se, portanto, de um tema bastante vasto que ainda ocupa de forma muito relevante os estudos em neuropsicologia e neurolinguística nestas primeiras décadas do século XXI.

Este artigo objetiva, sobretudo, (i) apresentar e discutir essas diferenças teóricas, à luz da Neurolinguística de orientação enunciativo-discursiva, com foco nas afasias e no funcionamento integrado dos níveis linguísticos (JAKOBSON, 1954; COUDRY, 1988 [1986]) e (ii) dar visibilidade a esse funcionamento integrado (LURIA, 1976; COUDRY, 1988 [1986]); (NOVAES-PINTO, 1992, 1999) por meio da análise de dados produzidos em contextos dialógicos com sujeitos afásicos, cuja produção de linguagem se caracteriza pela chamada "fala telegráfica".

Seria impossível, neste trabalho, trazer uma revisão exaustiva da literatura. Opto, assim, por sintetizar algumas das reflexões sobre o tema que vêm sendo desenvolvidas no âmbito do Grupo de Estudos da Linguagem no Envelhecimento e nas Patologias (GELEP) ${ }^{5}$, com foco na fala telegráfica. Não serão aprofundados neste texto os aspectos metodológicos das pesquisas ${ }^{6}$, mas vale ressaltar, para os objetivos aqui estabelecidos, que os estudos

alguma, a importância da neuroimagem para os estudos neuropsicológicos e, em especial, para os diagnósticos de lesões e processos degenerativos. Entretanto, é necessário refletir sobre seus limites explicativos, já que as imagens resultam de uma interpretação estatística dos dados. (NOVAES-PINTO, 2011).

5 Nossas pesquisas sobre as afasias têm como lócus o Centro de Convivência de Afásicos (CCA). Coordeno o Grupo 3, do qual participam sujeitos afásicos, alunos da graduação e pós-graduação.

6 A respeito dos dilemas metodológicos no campo dos estudos das afasias, ver Novaes-Pinto (2006): Desafios metodológicos da pesquisa neurolinguística no início do século XXI. 
são desenvolvidos na perspectiva qualitativa, privilegiando dados que emergem em contextos interativos. As análises, de cunho microgenético, têm aporte principalmente nos trabalhos de Vygotsky (1984) ${ }^{7}$ e fundamentam-se na produção e na compreensão do "enunciado", tal como postulado por Bakhtin (1997) ${ }^{8}$.

\section{Sobre o agramatismo e a produção da fala telegráfica}

O agramatismo é uma das categorias clínicas mais estudadas dentre os distúrbios afásicos. Nas palavras de Resnik (1997), trata-se de um fenômeno "testemunha", que se prestou às mais diversas interpretações ao longo da história de seus estudos e que reflete não apenas movimentos teóricos produzidos na Linguística, mas também certos enfoques neuropsicológicos. Segundo Kean (1985), há um consenso de que o agramatismo seja um distúrbio distinto dos demais fenômenos linguísticos presentes nas afasias e que, por isso, nenhuma perspectiva unitária daria conta de descrevê-lo e explicálo. Algumas de suas descrições datam de mais de um século e questões postuladas pelos neuropsicólogos clássicos ainda estão na agenda dos estudos contemporâneos (NOVAES-PINTO, 1999).

Segundo Goodglass e Menn (1985), o agramatismo foi inicialmente descrito por Deleuze, em 1819, como uma característica marcante na fala de certos pacientes afásicos, o que aponta para o fato de que, já nos primeiros estudos, houve uma equivalência entre essa categoria e a chamada "fala telegráfica" - sua característica mais marcante. De acordo com Tissot, Mounin e Lhermitte (1973), esses fenômenos foram abordados exclusivamente em termos de sua estrutura de produção, com destaque para as seguintes características:

- apagamento de palavras funcionais no discurso, isto é, de conjunções, preposições, artigos,

- $\quad$ pronomes, verbos auxiliares e cópulas (com exceção das conjunções and e because);

- predominância de substantivos, em detrimento dos verbos, em algumas falas agramáticas;

- perda da flexão, substituída pela forma nominal do verbo;

- perda de concordância de pessoa, número e gênero, notadamente em línguas flexionais.

7 Segundo Vygotsky (1984, p. 74), "a procura de um método torna-se um dos problemas mais importantes de todo empreendimento para a compreensão das formas caracteristicamente humanas de atividade psicológica [...]". Acerca desses conceitos e de sua relevância para a pesquisa na área, ver Novaes-Pinto $(1999,2004,2011)$ e Cazarotti-Pacheco $(2012,2016)$.

8 Acerca da produtividade dos conceitos bakhtinianos para descrever e analisar os dados que emergem no contexto das afasias, ver Novaes-Pinto (1999, 2004), Novaes-Pinto e Oliveira (2016) e Oliveira (2015). 
Vemos que todas as características mencionadas são definidas pelo prisma das perdas. Essa visão decorre da crença de que a lesão neurológica destrói tecidos cerebrais responsáveis por aspectos específicos da linguagem, o que por sua vez acarretaria a perda de uma competência específica. O conjunto de questões sintetizadas por Linnebarger, Schwartz e Saffran (1983) reforçam essa concepção:

- Há subcomponentes independentes no sistema de processamento da linguagem?

- Esses subcomponentes são descritíveis em termos de "níveis de representação" na teoria linguística?

- Tais componentes podem ser associados a áreas especificas do cérebro?

Nespolous (1993), pesquisador que vem se dedicando há décadas ao estudo do agramatismo, discorda da abordagem que o toma como um déficit sintático central que impacta a competência linguística. A esse respeito, o autor faz as seguintes ponderações:

Como a falha da competência linguística pode explicar a variabilidade ${ }^{9}$ das performances, que se observa na quase totalidade dos pacientes? Uma palavra, não produzida num dado momento, é produzida alguns instantes mais tarde; uma frase, produzida num momento de forma agramática, pode aparecer menos agramática, ou mesmo sem agramatismo em outro momento. Uma alteração da competência linguística não deveria desembocar em alterações estáveis (i.e. nãovariáveis) e permanentes? Seria razoável considerar que a recuperação - qualquer que seja a sua importância e ritmo - impõe a integração de uma competência? Mais do que uma adaptação das performances às novas condições impostas pela lesão cerebral? (NESPOLOUS, 1993, p. 3).

\section{O funcionamento integrado dos níveis linguísticos: do fonológico ao discursivo}

Desde a chamada de Jakobson (1954) aos linguistas, para que se voltassem aos estudos das afasias, pesquisadores da área - sobretudo da sintaxe - viram no agramatismo uma importante fonte de dados para o estabelecimento de hipóteses e de modelos de processamento da linguagem. Jakobson elegeu o agramatismo como o protótipo das

9 Dediquei a minha pesquisa de Doutorado (NOVAES-PINTO, 1999) ao estudo da variação que caracteriza não apenas o agramatismo, mas outras "categorias clínicas". Ao invés de descartar as categorias por conta das variações inter- e intra-individuais, busquei compreendê-las, justamente remetendo as diferenças ao trabalho que o sujeito afásico, apesar do impacto da lesão neurológica, continua operando sobre os recursos da língua, no processo de elaboração de seus enunciados, únicos e irrepetíveis, assim como os sujeitos. Esta temática está sendo desenvolvida no trabalho de Lima (2019), doutorado que se desenvolve com minha orientação. 
dificuldades de combinação das unidades linguísticas, em oposição à jargonafasia, na qual o sujeito teria predominantemente dificuldades com a seleção lexical. O autor alerta para o fato de que os dois eixos da linguagem - paradigmático e sintagmático - são projetados um sobre o outro. Isso significa que para que uma unidade seja combinada à outra no eixo sintagmático, ela precisa ser selecionada dentre as muitas unidades possíveis dentro de um determinado paradigma (fonético/fonológico e morfo-lexical). Esse funcionamento explicaria como um mesmo fenômeno, com materialidade na produção da fala telegráfica, pode ser explicado tanto como uma dificuldade de "acesso lexical" - sobretudo do léxico funcional - ou como uma dificuldade sintática propriamente dita - na combinação de unidades morfológicas e lexicais.

Nespolous e Dordain (1995) sintetizaram a variedade de pontos de vista na literatura neuropsicológica acerca dos processos responsáveis pelo agramatismo, com enfoque em um ou em outro nível linguístico. Questionaram qual componente da gramática se encontraria alterado, se é que um único componente poderia estar comprometido isoladamente: seria o componente sintático - como sugere a maioria dos autores - ou o componente fonológico -, como defendem os trabalhos de Kean (1979, 1980)? Poderia, ainda, defender-se a dificuldade no acesso lexical, como apontam Bradley, Garrett e Zuriff $(1980)^{10}$. Ainda sobre essa questão, Menn e Obler (1985) acreditam que a fala laboriosa e lenta, composta de sentenças fragmentadas, caracteriza-se por um output limitado dos recursos linguísticos sintáticos e morfológicos. Menn e Martohardjono (2016) concluíram, após a realização de um trabalho experimental, que a explicação morfológica é mais robusta do que a hipótese fonológica defendida por Kean.

$\mathrm{Na}$ literatura neurolinguística destacam-se os estudos realizados por Grodzinsky, na década de 80, quando relacionou a fala telegráfica ao apagamento dos vestígios na estrutura gramatical. Com base nos estudos deste autor, Gregolin-Guindaste (1996) ${ }^{11}$ defendeu que o agramatismo caracteriza-se por um distúrbio de natureza sintática. Segundo a autora, a produção do sujeito "P"12 não poderia ser explicada pela dificuldade

10 A abordagem de Kean (1980), segundo a qual o agramatismo deriva de dificuldades com o acesso fonológico, por exemplo, centra-se na ideia de que seriam preservados os morfemas tônicos das palavras ou sentenças, em detrimento dos morfemas gramaticais (flexionais e derivacionais). Isso explicaria, por exemplo, a predominância de formas nominalizadas dos verbos na fala telegráfica, a presença de substantivos e de outras categorias de classes abertas e, consequentemente, a ausência de palavras funcionais (GOODGLASS; MENN, 1985). De acordo com Goodglass e Menn (1985), a hipótese de Bradley et al. (1980) também concebe o agramatismo como um déficit de processamento dos morfemas gramaticais.

110 trabalho de Gregolin-Guindaste (1996) sobre o agramatismo foi orientado por Coudry, no campo da Neurolinguística. A autora realizou um estudo longitudinal, focando a produção de preposições ao longo do tempo em que ele frequentou o CCA.

120 sujeito "P" era um dos afásicos acompanhados longitudinalmente por Coudry em sua pesquisa de doutorado, concluída em 1986. As produções de " $P$ " foram estudadas por GregolinGuindaste (1996) e por Novaes-Pinto (1992, 1999). 
de encontrar palavras. O acesso ao léxico seria "bloqueado" em face de uma dificuldade sintática. A solução do sujeito para driblar suas dificuldades comunicativas, por outro lado, seria de ordem pragmática ${ }^{13}$. Para Gregolin-Guindaste (1996), o nível pragmático teria uma representação e funcionamento independentes, interagindo com os demais níveis formais apenas na formulação da "sentença", no ato comunicativo. Nossas análises, por outro lado, dão visibilidade ao papel central do contexto pragmático-discursivo para as operações de seleção e combinação. As operações pragmáticas não entrariam em jogo apenas na elaboração (produção) da sentença nos níveis hierárquicos mais altos, mas estariam subjacentes à seleção das unidades mais elementares (fonológicas, morfológicas e semântico-lexicais).

Nespolous e Dordain (1993) também consideram que há efeitos de uma eventual entrada em jogo de estratégias adaptativas pelos indivíduos afásicos, de natureza pragmáticodiscursivas. Dentre os autores que mais enfatizaram que a fala telegráfica é o resultado da adaptação do sujeito às novas condições impostas pelas afasias estão Kolk e seus colaboradores. A abordagem por eles defendida ficou conhecida como "Teoria da Adaptação", segundo a qual o agramático deveria ser considerado um super-gramático ${ }^{14}$ (KOLK; GRUNSVEN; KEISER, 1985). Apesar das dificuldades, o sujeito escolheria adequadamente as palavras mais relevantes, considerando sua carga semântica, e as ordenaria segundo as coordenadas contextuais da interação: o tema discursivo, os interlocutores etc. Questões como essas levaram Nespolous e Dordain (1993) a incorporar os estudos pragmáticos para abordar tanto as dificuldades dos afásicos, quanto a adaptação que os sujeitos agramáticos desenvolvem.

Com base na produção sobre o agramatismo, sobretudo no final da década de 70 e início dos anos 80 do século XX, Caramazza e Berndt (1985) concluem que este fenômeno deve ser concebido como um distúrbio multi-componencial ou panlinguístico, envolvendo a interação dos vários componentes linguísticos. Menn e Martohardjono (2016) referemse a trabalhos mais recentes que seguem essa direção, abordando as interfaces entre o discurso e a sintaxe (AVRUTIN, 2000) ou entre aspectos morfossintáticos e lexicais (THOMPSON; FIX; GITELMAN, 2002). Embora mais amplos do que os anteriores, esses modelos partem da concepção de que os níveis linguísticos possam ser afetados seletivamente, ou seja, de forma independente. Em outras palavras, os componentes interagem, o que não significa que sejam integrados, como defendemos a partir dos

13 A autora atribuiu a evolução do quadro de "P" ao trabalho realizado no Centro de Convivência de Afásicos (CCA) e afirmou que as "soluções" dadas pelo sujeito para lidar com as dificuldades sintáticas podem ser explicadas por sua competência pragmática.

14 Esta teoria tem sido criticada por desconsiderar, por exemplo, que há sujeitos que de fato não conseguem produzir palavras funcionais e a morfologia flexional, mesmo tendo todo o tempo disponível para elaborar seus enunciados. 
pressupostos de Jakobson e, mais recentemente, de acordo com os postulados da Gramática Funcional do Discurso (GFD) ${ }^{15}$.

\title{
A integração dos níveis linguísticos: evidências dos estudos das afasias na perspectiva enunciativo-discursiva
}

Um dos primeiros trabalhos a apresentar uma crítica sobre a aplicação dos modelos estruturalista e gerativista aos fenômenos afasiológicos foi o de Coudry e Possenti (1983). Os autores ressentiam-se, na época, do fato de que alguns avanços nos estudos linguísticos - como os discursivos - não haviam ainda repercutido em áreas em que a linguagem era um dos polos de uma relação interdisciplinar, como a Neurolinguística. Segundo eles, tais estudos poderiam provocar um deslocamento da noção de "patológico" na área dos estudos afasiológicos e, consequentemente, uma reinterpretação de muitos fenômenos e categorias.

A pesquisa de doutorado de Coudry, defendida em 1986 e publicada em 1988 como Diário de Narciso: discurso e afasia ${ }^{16}$, criticou as formulações fundamentadas em uma concepção de língua como código, sobretudo porque a avaliação dos "sintomas" é feita exclusivamente por meio de protocolos metalinguísticos que descartam das análises justamente os aspectos subjetivos da atividade linguística. A autora destaca, em seu trabalho inaugural, o conceito de linguagem como atividade, tal como foi proposta por Franchi (1977b). Retomo aqui uma passagem do autor porque o conteúdo relaciona-se ao tema central deste artigo:

\begin{abstract}
A linguagem, pois, não é um dado ou um resultado; mas um trabalho que dá forma ao conteúdo variável de nossas experiências, trabalho de construção, de retificação do vivido que, ao mesmo tempo, constitui o sistema simbólico mediante o qual se opera sobre a realidade e constitui a realidade como um sistema de referências em que aquele se torna significativo. Um trabalho coletivo, em que cada um se identifica com os outros e a eles se contrapõe, seja assumindo a história e a presença, seja exercendo suas opções solitárias (FRANCHI, 1977b, p. 22).
\end{abstract}

15 Pela natureza deste artigo, não será possível aqui articular os princípios da GFD às análises da fala telegráfica. Esta articulação vem sendo desenvolvida por Lima $(2017,2019)$ e será objeto de publicação futura.

16 Diário de Narciso: discurso e afasia foi publicado pela Martins Fontes em 1988 e deriva da tese de doutorado da autora, defendida em 1986 no Instituto de Estudos da Linguagem, Unicamp. Neste artigo, ambas as datas serão referidas, uma vez que a primeira diz respeito à "fundação" da área de estudos, a Neurolinguística enunciativo-discursiva ou, como a autora vem se referindo atualmente, a Neurolinguística Discursiva. 
A noção de "trabalho" é essencial para a perspectiva sócio-histórico-cultural que adotamos em nossos estudos. A linguagem é um trabalho que constitui ao mesmo tempo o sujeito e o próprio sistema da língua. Esse conceito é central também na teoria bakhtiniana, à qual recorremos desde 1999 para compreender os enunciados no contexto das afasias. Bakhtin (1997) postula o "enunciado" como unidade real da comunicação verbal. Essa unidade é contraposta à sentença ou à oração, não só em termos extensionais, mas também em termos qualitativos. De acordo com o autor, a fala só existe na sua forma concreta nos enunciados de um indivíduo (BAKHTIN, 1997 [1979]). Os sujeitos reais, segundo Bakhtin, "trabalham sobre os recursos da língua" - recursos lexicais, morfológicos, sintáticos para produzir enunciados concretos, como observamos na seguinte passagem:

O sistema da língua dispõe de uma reserva imensa de recursos puramente linguísticos para expressar formalmente o ato vocativo: recursos lexicais, morfológicos (as flexões correspondentes, os pronomes, as formas pessoais dos verbos), sintáticos (os diferentes clichês e as modificações das orações). Essas formas, porém, só podem implicar um destinatário real no todo de um enunciado concreto. Esses recursos especializados da língua (recursos gramaticais) jamais abrangem, claro, todas as expressões pelas quais a fala se dirige a um destinatário. Certos recursos linguísticos podem até estar completamente ausentes; ainda assim o enunciado refletirá, com grande agudeza, a influência do destinatário e de sua presumida reação-resposta. É sob uma maior ou menor influência do destinatário e de sua presumida reação-resposta que o locutor seleciona todos os recursos linguísticos de que necessita. (BAKHTIN, 1997, p. 326).

Inspirada pelas questões brevemente sintetizadas até aqui acerca do agramatismo e, sobretudo, pelo trabalho de Coudry (1988 [1986]) com o sujeito "P", passei a estudar o fenômeno do agramatismo (NOVAES-PINTO, 1992) com interesse na dificuldade que esse indivíduo afásico apresentava para julgar a gramaticalidade de sentenças. A avaliação foi baseada no teste de Linnebarger, Schwartz e Saffran (1983), que foi traduzido e adaptado para as características sintáticas do Português ${ }^{17}$. Os resultados evidenciaram as dificuldades de P para lidar com as palavras funcionais e foi possível deduzir que as análises que fazia das sentenças apoiavam-se em sua competência pragmática. Os dados que se seguem têm o intuito de ilustrar o tipo de julgamento gramatical que fazia:

(i) Irn: ${ }^{18 *}$ Carta cheia erros.

P: Ruim.

Irn: Por quê?

P: Carta... erro... não pode!

170 teste não foi validado para aplicação clínica. Serviu apenas aos propósitos da pesquisa de Mestrado.

18 Irn é a sigla para "Interlocutora + iniciais do nome da pesquisadora. 
(ii) Qual parente você acha que vem à sua casa hoje?

P: Nenhum!

(iii) O ladrão tentou escapar pela janela.

P: Ruim.

O sujeito P não deixou de operar metalinguisticamente sobre as sentenças do teste, mas estas só podiam ser compreendidas por ele como enunciados concretos, interpelados em sua unicidade, em relação ao seu contexto. Por mais que ele tenha sido esclarecido acerca do tipo de julgamento que teria que fazer, foi sua competência discursivo-pragmática que orientou a atividade linguística.

Em uma interação com outro sujeito afásico - OJ - que apresentava um quadro "típico" de fala telegráfica, solicitei que ele nomeasse a figura de uma pirâmide ${ }^{19}$. OJ olhou para o desenho e, depois de um longo intervalo de tempo, disse: "Eu... São Sebastião do Paraíso. Você?" Minha hipótese é a de que OJ, em face da dificuldade para produzir a palavra "pirâmide", recorreu a conhecimentos pragmáticos compartilhados com sua interlocutora para assegurar a ela que (i) sabia o que era a figura e (ii) sabia seu nome, embora não conseguisse produzi-lo20.

A estratégia desenvolvida por OJ me permitiu inferir que a imagem acústica (forma fonológica) da palavra "pirâmide" estaria preservada, ao menos parcialmente. Em outras palavras, OJ trilhou esse caminho para indicar que ele "sabia" a palavra que buscava (pirâmide) e que ela tinha a mesma "forma fonológica" inicial da palavra "Piracicaba" única resposta possível para sua pergunta: "Você?".

Este dado, que julgo singular ${ }^{21}$, revela indícios do funcionamento integrado entre a imagem acústica da palavra e seu conceito, como postulou Saussure (1916) ao tratar da natureza indissociável do signo linguístico, bem como remete às teorias desenvolvidas por Luria (1976) acerca dos enlaces fonológicos que constituem o funcionamento lexical.

19 Teste de Nomeação de Boston (TNB), de Goodglass e Kaplan (1986).

20 A afasia que deriva de lesões no córtex cerebral frontal são caracterizadas como motoras. No caso de OJ, o sujeito tem uma afasia motora do tipo eferente, cuja maior dificuldade seria a de passar suavemente de uma posição articulatória à outra, apesar de posicionar corretamente os articuladores. A esse respeito, ver Luria (1976).

210 dado singular, no sentido que Ihe atribui Abaurre (1996), é também concebido por Coudry (1996) como dado-achado. Cazarotti-Pacheco (2016), a esse respeito, afirma dados singulares, analisados microgeneticamente, permitem inferir sobre o funcionamento da linguagem e sua relação com outros processos cognitivos, tanto na normalidade quanto nas patologias. 


\section{Considerações finais}

É possível observar, nos exemplos apresentados, que o funcionamento pragmático é alçado ao centro do processo de significação justamente para que a gramática - entendida em seu sentido mais amplo (não estritamente forjada a partir de regras sintáticas, mas considerando-se a integração dos aspectos morfossintáticos, semânticos, pragmáticos e discursivos) - seja reorganizada ao longo do processo interativo. Tal integração resulta do trabalho do sujeito sobre os recursos da língua para produzir enunciados concretos.

Para dar conta dessa integração, Lima $(2017,2019)$ tem analisado o "enunciado de estilo telegráfico"22 à luz dos princípios teórico-metodológicos da Gramática Funcional do Discurso (GFD).

Subjacente às diferentes hipóteses da produção da fala telegráfica, pode-se afirmar que ainda hoje na literatura neuropsicológica predomina a visão de que os níveis linguísticos sejam autônomos e podem ser impactados seletivamente. Cada uma das correntes teóricas foca seu olhar para o nível que julga impactado, colocando-o em evidência nas análises, enquanto suspende os demais. Os procedimentos metodológicos (no campo da Neuropsicologia e mesmo da chamada "Psico-Neurolinguística) - de natureza metalinguística - são, por sua vez, elaborados para dar evidência a cada uma das hipóteses. Isso éjustificável do ponto de vista do estabelecimento de modelos, mas tornase uma abordagem bastante limitada quando contraposta à complexidade do fenômeno linguístico em seu funcionamento concreto.

Lembro que tal discussão já se encontrava bastante avançada nos estudos de Coudry quase uma década antes (no início dos anos 80), quando a autora afirmava que as afasias decorrem de alterações no funcionamento integrado dos níveis linguísticos e não de perdas específicas em um ou outro componente, o que culminou na definição formulada pela autora: as afasias são alterações de linguagem decorrentes de lesões cerebrais focais, provocadas pelos AVCs (derrames), tumores e TCEs (traumas crânio-encefálicos), dentre outros fatores etiológicos, e podem comprometer a atividade linguística em todas as suas modalidades: oral (produção e compreensão) e escrita - leitura e produção" e em todos os níveis linguísticos: fonético/fonológico, sintático, semântico-lexical, pragmáticodiscursivo (COUDRY, 1988 [1986]). Coudry (1988 [1986]) compara o funcionamento da linguagem dos afásicos a uma imagem mostrada em câmera lenta, na qual é possível apreender aspectos de sua composição que não poderiam ser percebidos na dinâmica e

22 Lima (2017) propôs a expressão "enunciado de estilo telegráfico", coerente com as teorias sóciohistórico-culturais que fundamentam nossas abordagens das afasias. O conceito de enunciado tal como postulado por Bakhtin (1997) dá conta de produções bastante reduzidas, muitas vezes sem significado no plano da língua. Em seu trabalho de doutorado (em desenvolvimento), Lima articula os princípios teórico-metodológicos da GDF nas análises dos enunciados telegráficos. 
velocidade normais. A afasia quebra ou dissocia o que, em princípio, está integrado; o que é indissociável no funcionamento normal da linguagem (LIMA; NOVAES-PINTO, 2017).

Fechando esta reflexão, trago as palavras de Jakobson (1954, p. 10), que sintetiza a proposta que discutimos neste artigo: "Não podemos verdadeiramente isolar elementos, mas tão somente distingui-los. Se os tratarmos separadamente no processo de análise linguística, deveremos sempre lembrar-nos do caráter artificial de tal separação".

\section{REFERÊNCIAS}

ABAURRE, M. B. Os estudos linguísticos e a aquisição da escrita. In: CASTRO, M. F. (org.). O Método e o Dado no Estudo da Linguagem. Campinas: Editora da UNICAMP, 1996. p. 111164.

AVRUTIN, S. Comprehension of discourse-linked and non-discourse-linked questions by children and Broca's aphasics. In: GRODZINSKY, Y.; SHAPIRO, L.; SWINNEY, D. (ed.). Language and the Brain: Representation and Processing. San Diego: Academic Press, 2000. p. 295-313.

BAKHTIN, M. O enunciado, a unidade da comunicação verbal. In: BAKHTIN, M. Estética da criação verbal. São Paulo: Martins Fontes, 1997. p. 289-327.

BRADLEY, D. C; GARRETT, M. F.; ZURIFF, E. B. Sintactic Deficits in Broca's afasia. In: CAPLAN, D. (org.). Biological studies of mental processes. Cambridge: MIT Press, 1980. p. 269-286.

CARAMAZZA, A.; BERNDT, R. A Multicomponent Deficit View of Agrammatic Broca's afasia. In: KEAN, M. (org.). Agrammatism. New York: Academic Press, 1985. p. 27-62.

CAZAROTTI-PACHECO, M. Contribuições da análise microgenética às pesquisas em neurolinguística. Estudos Linguísticos, v. 45, n. 2, p. 582-594, 2016.

CAZAROTTI-PACHECO, M. O discurso narrativo nas afasias. 2012. Tese (Doutorado em Linguística) - Instituto de Estudos da Linguagem, Universidade Estadual de Campinas, Campinas, 2012.

COUDRY, M. I. O que é o dado em neurolinguística? In: CASTRO, M. F. (org.). O Método e o Dado no Estudo da Linguagem. Campinas: Editora da UNICAMP, 1996. p. 179-194. 
COUDRY, M. I. Diário de Narciso - discurso e afasia. São Paulo: Martins Fontes, 1988.

COUDRY, M. I.; POSSENTI, S. Avaliar Discursos Patológicos. Cadernos de Estudos Linguísticos, v. 5, p. 99-109, 1983.

DAMÁSIO, A. What a difference a decade makes. Current Opinion in Neurology, lowa, U.S.A: Rapid Science Publishers, v. 20, p. 177-178, 1997.

FRANCHI, C. Hipóteses para uma análise funcional da linguagem. 1977. Tese (Doutorado em Linguística) - Instituto de Estudos da Linguagem, Universidade Estadual de Campinas, Campinas, 1977a.

FRANCHI, C. Linguagem - Atividade Constitutiva. Almanaque, 5. São Paulo: Brasiliense, 1977b. p. 9-27.

FREUD, S. A interpretação das afasias. Lisboa: Edições 70, 1871.

GOODGLASS, H.; KAPLAN, J. Evaluación de La Afasia y Transtornos Relacionados. Madrid: Editorial Medica Panamericana (Spanish adaptation by José E. Garcia-Albea; M.L Sánchez Bernardos). Original Title: The assessment of Aphasia and Related Disorders, 1996.

GOODGLASS, H.; MENN, L. Is Agrammatism a Unitary Phenomenon? In: KEAN, M. L. Agrammatism. New York: Academic Press, 1985. p. 1-25.

GRODZINSKY, Y. The syntactic characterization of Agrammatism. Cognition, v. 16, p. 99120, 1984.

GREGOLIN-GUINDASTE, R. O agramatismo: um estudo de caso em Português. 1996. Tese (Doutorado em Linguística) - Instituto de Estudos da Linguagem, Universidade Estadual de Campinas, Campinas, 1996.

JAKOBSON, R. Dois aspectos da linguagem e dois tipos de afasias. In: JAKOBSON, R. Linguística e Comunicação. São Paulo: Cultrix, 1954.

JACKSON, J. H. On the Nature of the Duality of the Brain. The Medical Press and Circular, v. 1, p. 41-44, 1874.

KEAN, M. L. Agrammatism. New York: Academic Press, 1985. 
KEAN, M. L. Grammatical representations and the description of language processes. In: KAPLAN, D. (ed.). Biological studies of mental processes. Cambridge: MIT Press, 1980.

KEAN, M. L. Agrammatism, a phonological deficit? Cognition, p. 69-83, 1979.

KLEPPA, L. Preposições ligadas a verbos na fala de uma criança em processo de aquisição de linguagem e de dois sujeitos agramáticos em processo de reconstrução de linguagem ou "Eu e você? Diferente". 2008. Tese (Doutorado em Linguística) - Instituto de Estudos da Linguagem, Universidade Estadual de Campinas, Campinas, 2008.

KOLK, H.; GRUNSVEN, M.; KEISER, A. On parallelism between production and comprehension in agrammatism. In: KEAN, M. Agrammatism. New York: Academic Press, 1985. p. 165-203.

LIMA, A. R. Uma abordagem funcional para os enunciados de estilo telegráfico: contribuições para estudo da relação entre pensamento e linguagem. Projeto de Doutorado-Sanduíche. Fapesp, 2019.

LIMA, A. R. As palavras funcionais na chamada "fala telegráfica" em enunciados de sujeitos afásicos. 2017. Dissertação (Mestrado em Linguística) - Instituto de Estudos da Linguagem, Universidade Estadual de Campinas, Campinas, 2017.

LIMA, A. R.; NOVAES-PINTO, R. C. A chamada "fala telegráfica" e sua relação com as dificuldades de encontrar palavras: uma reflexão a partir de enunciados de sujeitos afásicos não-fluentes. Estudos Linguísticos, v. 46, n. 2, p. 715-729, 2017.

LINNEBARGER, M.; SCHWARTZ, M. F.; SAFFRAN, E. M. Sensitivity to grammatical structure in so-called agrammatic aphasics. Cognition, v. 13, p. 361-392, 1983.

LURIA, A. Pensamento e Linguagem: as últimas conferências de Luria. Porto Alegre: Artes Médicas Editora, 1976.

LURIA, A. The working brain. London: Penguin Books, 1973.

MENN, L.; OBLER, L. K. Theoretical motivations for the cross-language study of agrammatism. In: MENN, L.; OBLER, L. Agrammatic Aphasia: A cross-language narrative study. Amsterdam: John Benjamin Publishing Company, 1990. p. 3-12. 
MENN, L.; MARTOHARDJONO, G. Morphological vs. phonological explanations for affix errors in agrammatism. Aphasiology, v. 31, n. 8, p. 1-23, 2016.

NESPOLOUS, J. L. A contribuição das ciências cognitivas - e, particularmente, da Psicolinguística cognitive - ao estudo das alterações de linguagem ou "do descritivo ao interpretative. In: RODRIGUES, N.; MANSUR, L. Temas em Neuropsicologia. Série de Neuropsicologia, 1993. v. 1, p. 19-37.

NESPOLOUS, J. L.; DORDAIN, M. Agramatismo: Alteração sintática ou Morfemática? Um estudo de caso. In: MANSUR, L.; RODRIGUES, N. Temas em Neurolinguística. Série de neuropsicologia, 1995. v. 2

NESPOLOUS, J. L. El agramatismo en vísperas del año 2000: reflexiones Y Perspectivas. Neuropsychologia Latina, Sociedad Latinoamericana de Neuropsicología, v. 3, p. 2-3, 1997.

NOVAES-PINTO, R. Desafios metodológicos da pesquisa em Neurolinguística no início do século XXI. Estudos Linguísticos, v. 40, n. 2, p. 966-980, 2011.

NOVAES-PINTO, R. A adoção de conceitos bakhtinianos para a análise de linguagem de sujeitos afásicos. Estudos da Lingua(gem), v. 1, p. 111-148, 2004.

NOVAES-PINTO, R. Contribuição de Conceitos Bakhtinianos para a Análise de Dados nas diferentes formas de afasias. Estudos Linguísticos, São Paulo, n. 32, 2003.

NOVAES-PINTO, R. A contribuição do estudo discursivo para uma análise crítica das categorias clínicas. 1999. Tese. (Doutorado em Linguística) - Instituto de Estudos da Linguagem, Universidade Estadual de Campinas, Campinas, 1999.

NOVAES-PINTO, R. C. Agramatismo: uma contribuição para o estudo do processamento normal da linguagem. 1992. Dissertação. (Mestrado em Linguística) - Instituto de Estudos da Linguagem, Universidade Estadual de Campinas, Campinas, 1992.

NOVAES-PINTO, R.; OLIVEIRA, M. V. Uncovering hidden meanings in legal discourse on the elderly: A semioethical perspective. Semiotica, Berlin, v. 2016, p. 301-321, 2016.

OLIVEIRA, M. V. B. Palavras na ponta-da-língua: uma abordagem neurolinguística. 2015. Tese (Doutorado em Linguística) - Instituto de Estudos da Linguagem, Universidade Estadual de Campinas, Campinas, 2015. 
PITRES, A. L'aphasie amnesique et ses variets cliniques. Progress med., 1898.

RESNIK, M. Agramatismo: categorias funcionales y agramatismo. Neuropsychologia Latina, v. 3, p. 11, 1997.

SAUSSURE, F. Cours de Linguistique Générale. Paris: Payot, 1916.

THOMPSON, C. K.; FIX, S.; GITELMAN, D. Selective impairment of morphosyntactic production in a neurological patient. Journal of Neurolinguistics, v. 15, p. 189-207, 2002.

TISSOT, R.; MOUNIN, F.; LHERMITTE, F. Agrammatisme. Étude neuropsycholinguistique. Bruxelles: Dessart. 1973.

VYGOTSKY, L. S. A Formação Social da Mente. São Paulo: Martins Fontes, 1984. 